\title{
Cortical developmental death: Selected to survive or fated to die
}

Frédéric Causeret*, 1,2, Eva Coppola*,1,2,3 and Alessandra Pierani ${ }^{1,2}$

* Equal contribution

1) Center for Psychiatry and Neurosciences, INSERM UMR 894, Université Paris Descartes, Sorbonne Paris Cité, Paris, France.

2) Imagine Institute, Université Paris Descartes, Sorbonne Paris Cité, Paris, France

3) Institut Jacques Monod, CNRS UMR 7592, Université Paris Diderot, Sorbonne Paris Cité, Paris, France

Corresponding Author: Alessandra Pierani (alessandra.pierani@inserm.fr)

Running Title: Developmental death in the cerebral cortex

Keywords: cell death; cerebral cortex; transient cells; Cajal-Retzius neurons; subplate neurons; interneurons; precursor of oligodendrocytes 


\begin{abstract}
The mature cerebral cortex only contains a fraction of the cells that are generated during embryonic development. Indeed some neuronal populations are produced in excess and later subjected to partial elimination whereas others are almost completely removed during the first two postnatal weeks in mice. Although the identity of cells that disappear, the time course and mechanisms of their death are becoming reasonably well established, the meaning of producing supernumerary cells still remains elusive. In this review, we focus on recent data that shed a new light on the mechanisms involved in adjusting cell numbers and discuss the significance of refinement versus complete elimination of cell populations in the developing cortex.
\end{abstract}

\title{
Introduction
}

Programmed cell death (PCD) is a biological process which serve crucial functions in the body. It is used to match numbers of distinct cell types in tissue homeostasis, to remove aberrant cells, to eliminate transient structures or to shape organ morphogenesis [1]. In the nervous system PCD finetunes the density of neuronal populations and their targets. The so-called trophic theory states that neurons compete for target-derived survival factors available in limited amounts, leading to the elimination of up to $50 \%$ of neurons [2-5]. Although this theory is largely supported by experimental evidences in the peripheral nervous system, it remains to be demonstrated in the central nervous system (CNS) where survival has not been linked formally to growth factor(s). Furthermore, in the cerebral cortex several populations of cells exist that almost completely disappear during the first two postnatal weeks. This seems to be a unique characteristic of the mammalian neocortex not reported in other territories of the nervous system and used in different organs to fully eliminate embryonic or unwanted structures such as patterning centers or sexspecific primordia [1].

Processes of cell death in the developing nervous system have been extensively reviewed elsewhere [4-8]. Here we will especially focus on the cerebral cortex and survey recent data shedding light on cell populations either subjected to partial elimination or complete removal during development and discuss the potential relevance of their disappearance in the construction of functional and dysfunctional neural circuits.

\section{Refinement of neuronal numbers versus complete removal in the developing cortex}

In the cerebral cortex, the existence of exuberant neurons and projections and their role during development has been studied for many years. Notably, an increase in transient axonal and cell populations has been suggested to correlate with the complexification of cortical circuits in primates [9]. While cellular processes like neurogenesis, migration, synaptogenesis or myelination are recognized building bricks for circuit formation, the role of transient cells and their PCD in the assembly of nascent cortical networks is still poorly understood. Both glutamatergic projection neurons and more recently GABAergic interneurons were shown to undergo significant cell death at early postnatal stages in mice, leading to the disappearance of $30-40 \%$ of both cell types $\left[10^{\bullet}, 11^{\circ}\right]$ (Figure $1 \mathrm{a}, \mathrm{d}$ and Table 1 ). In addition, four populations identified so far massively disappear at the end of cortical development: Cajal-Retzius neurons (CRs), subplate 
neurons (SPs), cortical plate transient neurons (CPTs) and the first wave of embryonic oligodendrocyte precursors (firstOPCs) $\left[12^{\bullet}, 13^{\bullet}, 14,1^{\circ}\right]$ (Figure 1a-c and Table 1).

Characterizing the lifespan of populations which disappear is not an easy task. Earlier works heavily relied on histological hallmarks of cell death - most notably pyknosis and DNA fragmentation which did not allow assessing cell identity. Activated Caspase-3 immunodetection has also been used extensively but given the short interval between Caspase cleavage and phagocytosis by macrophages (estimated to a few hours [16]) it is suitable only for studying populations which are either very large or that die synchronously over a short period of time. In addition, one should keep in mind the emerging roles of Caspase activation beyond apoptosis as well as Caspase-3 independent cell death [17-19]. On the contrary, lineage analysis in flies and nematodes, but also in mice thanks to genetic tracing, allows following cells throughout their life and unequivocally proving their absence or transformation during adulthood.

\section{Mechanisms of refinement}

It is well established that the neurotrophins NGF and NT-3 are required for the survival of most peripheral neurons. In the CNS, BDNF, which is the most expressed neurotrophin, does not display the same activity $[5,20]$. A very appealing explanation came with the discovery that both receptors for NGF and NT-3, TrkA and TrkC, but not the BDNF receptor TrkB, behave as "dependence receptors”, triggering cell death unless bound to their respective ligands [21,22]. Other growth factors such as IGF-1 and TGF-b1 were proposed to regulate cortical neuronal survival since their loss results in increased cell death $[23,24]$. However, their precise contribution to the selective elimination of cortical interneurons and projection neurons remains to be assessed. Southwell et al. [10] proposed that interneurons death is not mediated by competition for trophic factors but rather by an intrinsic program following the observation that upon heterochronic grafts, interneurons die according to their own birthdate and not that of their environment. Yet, our global understanding of developmental cell death in the cortex remains fragmentary, reflecting either the existence of multiple cell-type specific extracellular and intracellular pathways (reviewed by [8]) and/or the implication of alternative mechanisms that do not fit with the classical neurotrophic theory.

Synaptic transmission has long been suggested to play a key role in controlling the balance between cortical cell survival and elimination [5,7,25]. Accordingly, cortical cell death peaks during the first two postnatal weeks, coinciding with the emergence of chemical synapses (Figure 1b-d). Three elegant studies recently formally demonstrated that in vivo electrical activity regulates the extent of apoptosis in both excitatory neurons and interneurons. Comparison between primary motor and somatosensory areas indicated that the density of apoptotic cells is more important in the former whereas electrical activity is higher in the latter. Consistent with the idea that electrical activity favours survival, kainate-stimulated animals display decreased apoptosis in the motor cortex whereas sensory-deprivation results in increased apoptosis in primary somatosensory areas [26••]. Interneurons targeted genetically to express ion channels that either decrease or increase neuronal excitability are prone to elimination or survival respectively [27*0]. Consistently, interneurons expressing a DREADD (designer receptor exclusively activated by designer drug) that increases activity better survive when grafted in an early postnatal cortex [28*0]. Together these results 
highlight the general role of electrical activity as a mean for functional selection and refinement of cortical networks.

\section{Transient populations in the developing cortex}

The cerebral cortex appears to be original with respect to other parts of the nervous system as at least four populations massively (>90\%) disappear: CRs, SPs, CPTs and firstOPCs $\left[12^{\bullet}, 13^{\bullet}, 14,15^{\bullet}\right]$ (Figure 1a).

SPs comprise several neuron types and are essential for correct circuit assembly as transient targets of thalamocortical axons [14]. While earlier studies proposed that SPs massively disappear from the cortex [29], several reports suggest that at least part of them may persist in the postnatal brain [30-32] and/or merely diluted by increasing number of incoming axons in primates [33]. Given the heterogeneity of SPs and above all the lack of genetic tools to follow them throughout cortical development it remains unknown whether SPs undergo cell death.

By contrast, the disappearance of CRs, CPTs and firstOPCs has been formally proven by genetic tracing in mice. This allowed identifying the CPTs, a novel glutamatergic population which are present during embryonic life, participate in the radial growth of the neocortex in a non-cell autonomous manner and massively die during the first postnatal week in mice $\left[13^{\bullet}, 34\right]$. Genetic tracing was also instrumental in revealing that cortical OPCs are generated and eliminated with specific spatio-temporal patterns. A first wave, called firstOPCs, disappear by postnatal day 10 in mice when the oligodendrocyte production and myelination process have not started yet and were considered dispensable elements for cortical circuit formation [12]. However, recent reports showed that firstOPCs contribute to the blood vessel network formation and stabilization during late embryonic stages [35]. The evidence that these can survive when OPCs derived from the two following waves are ablated $\left[12^{\circ}\right]$ argues against the possibility that their elimination is solely controlled by an intrinsic and timely regulated program and suggests that in a competition for survival factors firstOPCs are less performing than other OPCs. The mechanisms underlying the massive disappearance of CPTs and firstOPCs still remain uncharacterized.

CRs disappearance has been extensively studied. These are generated at three main sources at the borders of the developing pallium, the cortical hem, septum and pallium-subpallium boundary (PSB). From these focal sites CRs migrate tangentially to cover the entire cortical surface (the future layer 1 ) and influence the organization of the developing cortex at multiple stages by releasing signals affecting the underlying neurons [36]. Within the first two postnatal weeks the layer 1 in the neocortex becomes almost completed depleted of CRs in rodents, to an extent which cannot be explained by simple dilution of these neurons in the growing cortex [37] (Figure 1a, c). Beyond confirming the global loss of 94-97\% of CRs [38,39], the use of mouse models in which CR subtypes were permanently labeled by genetic tracing allowed to exclude the hypothesis raised by Parnavelas [40] of CRs transfating into non-pyramidal neurons $\left[15^{\circ}, 41\right]$. Tracing distinct subtypes $\left[1^{\circ}\right]$ also revealed specific differences in the dynamics of CR death (PSB-derived CR die earlier) as well as in the molecular pathways involved. Indeed, conditional inactivation of the pro-apoptotic factor Bax gene in both hem- and septum-derived CRs could partially prevent their death whereas hem-specific Bax deletion had no effect on 
survival, suggesting that septum- but not hem-CR die in a Bax-dependent manner in the neocortex [15 ${ }^{\circ}$. Other death subroutine such as necroptosis or autophagy [18] may be active in cortical-hem derived CRs. This massive neural cell death is specific to CRs, while all GABAergic subtypes disappear in a Bax-dependent manner and with similar rate in layer 1 compared to other cortical layers $\left[10^{\bullet}, 42\right]$ suggesting that layer 1 is not merely a hostile environment.

The signals that trigger CRs death represent still an open question. Seminal studies from Del Rio [43] highlighted the role played by electrical activity on CRs' survival. Opposite to what described for cortical neurons (reviewed in [7]) global silencing of neural activity using TTX, a voltage-gated sodium channels blocker, decreased CRs death in vitro. Therefore the same biological process, i.e. integration in neural networks, is essential for cortical neuron survival and has detrimental effects on CRs [44 $\left.{ }^{\circ}\right]$, underlying that intrinsic differences specific to each neural population contribute to the program triggering cell death. An intriguing explanation may reside in the fact that CRs remain in "a state of persistent immaturity" in a mature circuits, thereby failing to adapt to the new postnatal environment as other cortical neurons do. One modification occurring in cortical neurons after birth and which is not observed in CRs is the shift of GABAergic response from depolarizing toward hyperpolarizing. The excitatory action of GABA on CRs is due to the persistence of the chloride inward transporter NKCC1 and absence of chloride outward transporter KCC2, resulting in an elevated intracellular $\mathrm{Cl}^{-}$ concentration in CRs. Interestingly, GABA activity was shown to be deleterious for CR survival and pharmacological inhibition or genetic deletion of NKCC1 reduced CR death.

It should also be considered the special case of the CRs residing in the hippocampus that derive mostly from the cortical hem [45] and behave differently from those found in the neocortex. Indeed, in the hippocampus CR death is delayed, it seems independent from Caspase-3 activity [46 ${ }^{\circ}$ and at late postnatal stages almost the double of CRs are found in this region compared to the neocortex [41]. Furthermore, exposure to an enriched environment increased CRs survival in the hippocampus but not in the neocortex, likely due to increased neurogenesis, hence highlighting the role played by the environment in determining the lifespan of CRs [41].

\section{Significance of developmental cell death in the neocortex}

Interfering with PCD results in severe brain malformations, as seen in Caspase knockout mice $[47,48]$. However, depending on the genetic background, such modifications may also remain almost silent [49], blurring our understanding of the physiological significance of removing a large fraction of neurons generated during development. Although highly unlikely regarding populations that completely disappear, the possibility exists that what we refer to as a "refinement in neuronal numbers" might actually reflect, in part, the elimination of abnormal cells (Figure 2a). It has been estimated that up to a third of embryonic cortical neuroblasts exhibit aneuploidy and that the fate of such cells is probably death [50], indicating that the number of abnormal cells generated during brain development is perhaps more important than one can anticipate. 
With an evolutionary perspective, it would be surprising that the cost of generating entire populations or even supernumerary cells is not balanced by some kind of advantage for the developing organism.

Circuit maturation is an obvious explanation. It is perhaps more efficient to generate larger networks than needed and subsequently select the most appropriate components (Figure 2). With this prism, the fact that glutamatergic neurons and inhibitory interneurons undergo similar reductions in their numbers should be remarked. However, this does not apply to populations that completely disappear, the death of which may rather reflect a transient function. One example could be the need to remove signals that are no longer needed (Figure 2c).

In support of this, the anterior neural ridge (ANR) acts as an organizing center releasing FGF8 which is essential to early regionalization. The ANR is also a highly apoptotic region and it was proposed that the removal of morphogen-secreting cells allows to shape the spatial and temporal FGF8 gradient in order to ensure correct cortical patterning [51]. Through the secretion of Reelin, CRs control radial neuronal migration, a process that is achieved at the time of their elimination [52]. In addition, both CRs and CPTs behave as transient signaling units [53], releasing a variety of diffusible signals that control progenitor proliferation and neuronal differentiation [34,54,55]. Beyond patterning centers, intermediate targets for growing axons and migrating neurons are also sources of signals and serve as "waiting” zones (Figure 2d). Indeed, transient neuronal populations were shown to serve as guidepost for crossing of callosal axons at the midline [56] and SPs for thalamocortical axons [14]. Similarly, both SPs and CRs are strategically located in the close vicinity of migrating interneurons incoming from the ganglionic eminences before they enter the cortical plate or connect with them. Moreover, CRs were shown to influence interneuron migration [57], a function that becomes obsolete once interneurons have settled in the cortical plate. Incidentally, cell elimination provides extra space to neighbor neurons (Figure 2e). For instance the marginal zone is massively depleted of cell bodies after CRs disappear, allowing the terminal dendritic arborization of pyramidal neurons to expand. Complete elimination of these transient populations could thus reflect the necessity to stabilize cortical networks by removing signals that influence their establishment or an intermediate target which could represent a functional or physical "barrier" to circuit maturation.

Lastly, PCD has been proposed to act as a signal per se (Figure 2f; see reviews [58,59]). Nonautonomous apoptosis-induced apoptosis has been described but its existence in the brain remain to be demonstrated. Apoptosis-induced proliferation on the other hand has been described in the cerebral cortex, and could represent a compensatory mechanism following injury. We have highlighted such processes by which cortical progenitors can change their behavior in response to major neuronal loss [60]. Thus, the possibility that the massive and synchronous death of transient cells at early postnatal stages is instructive for cortical development should perhaps not be ruled out.

\section{Future perspectives}

The persistence of CRs during postnatal life has been detected in pathological conditions such as temporal lobe epilepsy and polymicrogyria and that of SPs in pharmaco-resistant epilepsy, thereby highlighting that the lack of disappearance of transient populations might also contribute to the 
dysfunction of cortical circuits $\left[15^{\bullet}, 61\right]$. Interestingly, the abnormal presence of neurons in the white matter and aberrant circuits in the prefrontal cortex of schizophrenic patients has also been attributed to alterations in the pattern of PCD [62]. Notably, oligodendrocytes derived from embryonic ventral precursors, including firstOPCs, display a reduced capacity to produce myelin than those from postnatal dorsal regions and this difference mainly emerges in demyelinating lesions [63]. An abnormal survival of firstOPCs could thus also participate to pathologies related to myelin disorders.

Interestingly, if early born CRs in human appear to be transient, later waves, possibly specific to humans, were suggested to persist in the adult and their location correlated with the bottom of small sulci and ingrowing vasculature opening the intriguing possibility that increase number and lifespan might be needed in primates to serve specific evolutionary function ([64]. Similarly, the width of the subplate is most prominent in association areas whose size has specifically increased during cortical evolution [33].

While the requirement of transient cell populations during early cortical development is well accepted, it remains unknown whether their death at a precise postnatal age is necessary for late aspects of cortical maturation. Animal models rescuing death of specific populations, as those obtained for CRs, will help addressing the functional relevance of their complete removal. 


\section{Acknowledgements}

The authors apologize for not having been able to cite the work of many contributors to the field. We wish to thank Anne Teissier and Maria-Cecilia Angulo for helpful discussions and critical reading of the manuscript. A.P. is a CNRS (Centre National de la Recherche Scientifique) Investigators and member Teams of the École des Neurosciences de Paris Ile-deFrance (ENP), E.C. is a University Paris Diderot Lecturer, F.C is an Inserm researcher. This work was supported by grants from the ANR-15-CE16-0003-01) and FRM («Equipe FRM DEQ20130326521») to A.P and State funding from the Agence Nationale de la Recherche under “Investissements d'avenir” program (ANR-10-IAHU-01).

\section{Conflict of interest statement}

Nothing declared

\section{References}

1. Jacobson MD, Weil M, Raff MC: Programmed cell death in animal development. Cell 1997, 88:347-354.

2. Fuchs Y, Steller H: Programmed cell death in animal development and disease. Cell 2011, 147:742-758.

3. Oppenheim RW: Cell death during development of the nervous system. Annu Rev Neurosci 1991, 14:453-501.

4. Yamaguchi Y, Miura M: Programmed cell death in neurodevelopment. Dev Cell 2015, 32:478490.

5. Dekkers MP, Nikoletopoulou V, Barde YA: Cell biology in neuroscience: Death of developing neurons: new insights and implications for connectivity. J Cell Biol 2013, 203:385-393.

6. Nikolic M, Gardner HA, Tucker KL: Postnatal neuronal apoptosis in the cerebral cortex: physiological and pathophysiological mechanisms. Neuroscience 2013, 254:369-378.

7. Blanquie O, Kilb W, Sinning A, Luhmann HJ: Homeostatic interplay between electrical activity and neuronal apoptosis in the developing neocortex. Neuroscience 2017, 358:190-200.

8. Pfisterer $U$, Khodosevich $K$ : Neuronal survival in the brain: neuron type-specific mechanisms. Cell Death Dis 2017, 8:e2643.

9. Innocenti GM, Price DJ: Exuberance in the development of cortical networks. Nat Rev Neurosci 2005, 6:955-965.

-10. Southwell DG, Paredes MF, Galvao RP, Jones DL, Froemke RC, Sebe JY, Alfaro-Cervello C, Tang Y, Garcia-Verdugo JM, Rubenstein JL, et al.: Intrinsically determined cell death of developing cortical interneurons. Nature 2012, 491:109-113.

This is the first report that cortical interneurons undergo Bax-dependent cell death during postnatal development. Transplantation experiments indicated that interneurons die depending on their age rather than that of their host, leading to the proposition that their death is intrinsically determined. This hypothesis has been challenged by recent reports on the role of electrical activity [27, 28].

-11. Verney C, Takahashi T, Bhide PG, Nowakowski RS, Caviness VS, Jr.: Independent controls for neocortical neuron production and histogenetic cell death. Dev Neurosci 2000, 22:125-138.

Pioneer work describing the spatiotemporal distribution of $\mathrm{TUNEL}^{+}$cells in the postnatal mouse cortex, indicating that a substantial amount of cortical neurons are eliminated by apoptosis.

-12. Kessaris N, Fogarty M, Iannarelli P, Grist M, Wegner M, Richardson WD: Competing waves of oligodendrocytes in the forebrain and postnatal elimination of an embryonic lineage. Nat Neurosci 2006, 9:173-179.

By using precise genetic tracing in mice the authors document the ontogenetic heterogeneity among OPCs, which are born in three successive waves in mouse forebrain. They also show that the ablation 
of later born OPCs could be compensated by the earliest born OPCs, which normally disappeared, leaving open the question of functional redundancy amongst OPCs with different origins.

-13. Teissier A, Griveau A, Vigier L, Piolot T, Borello U, Pierani A: A novel transient glutamatergic population migrating from the pallial-subpallial boundary contributes to neocortical development. $J$ Neurosci 2010, 30:10563-10574.

The careful analysis of Dbx1 derivatives allowed identifying for the first time a population of tangentially migrating glutamatergic neurons, the CPTs, which populate the cortex during embryonic development but progressively disappear starting from the first postnatal week. Their specific ablation provoked a decrease in the thickness of cortical plate, highlighting the role of these transient neurons in controlling the radial growth of the neocortex.

14. Hoerder-Suabedissen A, Molnar Z: Development, evolution and pathology of neocortical subplate neurons. Nat Rev Neurosci 2015, 16:133-146.

-15. Ledonne F, Orduz D, Mercier J, Vigier L, Grove EA, Tissir F, Angulo MC, Pierani A, Coppola E: Targeted Inactivation of Bax Reveals a Subtype-Specific Mechanism of Cajal-Retzius Neuron Death in the Postnatal Cerebral Cortex. Cell Rep 2016, 17:3133-3141.

The first study characterising subtype-specific mechanisms of death in CR. It highlights that despite the massive demise of CRs by the end of the third postnatal week, the onset of CR death is not synchronous. Moreover, targeted inactivation of the proapoptotic factor Bax could not rescue hem-derived CRs, but was effective in making septum-derived CRs survive, showing that different molecular pathways control CR death in a subpopulation-specific manner.

16. Tawa P, Hell K, Giroux A, Grimm E, Han Y, Nicholson DW, Xanthoudakis S: Catalytic activity of caspase- 3 is required for its degradation: stabilization of the active complex by synthetic inhibitors. Cell Death Differ 2004, 11:439-447.

17. D'Amelio M, Sheng M, Cecconi F: Caspase-3 in the central nervous system: beyond apoptosis. Trends Neurosci 2012, 35:700-709.

18. Galluzzi L, Vitale I, Aaronson SA, Abrams JM, Adam D, Agostinis P, Alnemri ES, Altucci L, Amelio I, Andrews DW, et al.: Molecular mechanisms of cell death: recommendations of the Nomenclature Committee on Cell Death 2018. Cell Death Differ 2018, 25:486-541.

19. Tait SW, Green DR: Caspase-independent cell death: leaving the set without the final cut. Oncogene 2008, 27:6452-6461.

20. Rauskolb S, Zagrebelsky M, Dreznjak A, Deogracias R, Matsumoto T, Wiese S, Erne B, Sendtner $\mathrm{M}$, Schaeren-Wiemers $\mathrm{N}$, Korte $\mathrm{M}$, et al.: Global deprivation of brain-derived neurotrophic factor in the CNS reveals an area-specific requirement for dendritic growth. $J$ Neurosci 2010, 30:1739-1749.

21. Nikoletopoulou V, Lickert H, Frade JM, Rencurel C, Giallonardo P, Zhang L, Bibel M, Barde YA: Neurotrophin receptors TrkA and TrkC cause neuronal death whereas TrkB does not. Nature 2010, 467:59-63.

22. Tauszig-Delamasure S, Yu LY, Cabrera JR, Bouzas-Rodriguez J, Mermet-Bouvier C, Guix C, Bordeaux MC, Arumae U, Mehlen P: The TrkC receptor induces apoptosis when the dependence receptor notion meets the neurotrophin paradigm. Proc Natl Acad Sci U S A 2007, 104:1336113366.

23. Brionne TC, Tesseur I, Masliah E, Wyss-Coray T: Loss of TGF-beta 1 leads to increased neuronal cell death and microgliosis in mouse brain. Neuron 2003, 40:1133-1145.

24. Ueno M, Fujita Y, Tanaka T, Nakamura Y, Kikuta J, Ishii M, Yamashita T: Layer V cortical neurons require microglial support for survival during postnatal development. Nat Neurosci 2013, 16:543-551.

25. Ikonomidou C, Bosch F, Miksa M, Bittigau P, Vockler J, Dikranian K, Tenkova TI, Stefovska V, Turski L, Olney JW: Blockade of NMDA receptors and apoptotic neurodegeneration in the developing brain. Science 1999, 283:70-74.

••26. Blanquie O, Yang JW, Kilb W, Sharopov S, Sinning A, Luhmann HJ: Electrical activity controls area-specific expression of neuronal apoptosis in the mouse developing cerebral cortex. Elife 2017, 6.

The authors report an inverse correlation between electrical activity and apoptosis in distinct functional cortical areas. They use pharmacological agents and sensory deprivation to formally demonstrate that spontaneous and periphery-evoked activity regulate cell death in distinct cortical areas in vivo. 
••27. Priya R, Paredes MF, Karayannis T, Yusuf N, Liu X, Jaglin X, Graef I, Alvarez-Buylla A, Fishell G: Activity Regulates Cell Death within Cortical Interneurons through a CalcineurinDependent Mechanism. Cell Rep 2018, 22:1695-1709.

This paper was published back-to-back with [28]. The authors observed that the elimination of a subset of interneurons is compensated for by the increased survival of another population. They found that elevated cortical network or interneuron-intrinsic electrical activity favors survival.

••28. Denaxa M, Neves G, Rabinowitz A, Kemlo S, Liodis P, Burrone J, Pachnis V: Modulation of Apoptosis Controls Inhibitory Interneuron Number in the Cortex. Cell Rep 2018, 22:1710-1721. This paper was published back-to-back with [27]. The authors observed that the elimination of a subset of interneurons is compensated for by the increased survival of another population. They found that elevated cortical network or interneuron-intrinsic electrical activity favors survival.

29. Price DJ, Aslam S, Tasker L, Gillies K: Fates of the earliest generated cells in the developing murine neocortex. J Comp Neurol 1997, 377:414-422.

30. Marx M, Qi G, Hanganu-Opatz IL, Kilb W, Luhmann HJ, Feldmeyer D: Neocortical Layer 6B as a Remnant of the Subplate - A Morphological Comparison. Cereb Cortex 2017, 27:1011-1026.

31. Viswanathan S, Sheikh A, Looger LL, Kanold PO: Molecularly Defined Subplate Neurons Project Both to Thalamocortical Recipient Layers and Thalamus. Cereb Cortex 2017, 27:47594768.

32. Hoerder-Suabedissen A, Molnar Z: Molecular diversity of early-born subplate neurons. Cereb Cortex 2013, 23:1473-1483.

33. Duque A, Krsnik Z, Kostovic I, Rakic P: Secondary expansion of the transient subplate zone in the developing cerebrum of human and nonhuman primates. Proc Natl Acad Sci U S A 2016, 113:9892-9897.

34. Teissier A, Waclaw R, Griveau A, Campbell K, Pierani A: Tangentially migrating transient glutamatergic neurons control neurogenesis and maintenance of cerebral cortical progenitor pools. Cerebral Cortex 2012, 22:403-416.

35. Minocha S, Valloton D, Brunet I, Eichmann A, Hornung JP, Lebrand C: NG2 glia are required for vessel network formation during embryonic development. Elife 2015, 4:e09102.

36. Barber M, Pierani A: Tangential migration of glutamatergic neurons and cortical patterning during development: Lessons from Cajal-Retzius cells. Dev Neurobiol 2016, 76:847-881.

37. Kirischuk S, Luhmann HJ, Kilb W: Cajal-Retzius cells: update on structural and functional properties of these mystic neurons that bridged the 20th century. Neuroscience 2014, 275:3346.

38. Anstotz M, Cosgrove KE, Hack I, Mugnaini E, Maccaferri G, Lubke JH: Morphology, inputoutput relations and synaptic connectivity of Cajal-Retzius cells in layer 1 of the developing neocortex of CXCR4-EGFP mice. Brain Struct Funct 2014, 219:2119-2139.

39. Chowdhury TG, Jimenez JC, Bomar JM, Cruz-Martin A, Cantle JP, Portera-Cailliau C: Fate of cajal-retzius neurons in the postnatal mouse neocortex. Front Neuroanat 2010, 4:10.

40. Parnavelas JG, Edmunds SM: Further evidence that Retzius-Cajal cells transform to nonpyramidal neurons in the developing rat visual cortex. J Neurocytol 1983, 12:863-871.

41. Anstotz M, Lee SK, Neblett TI, Rune GM, Maccaferri G: Experience-Dependent Regulation of Cajal-Retzius Cell Networks in the Developing and Adult Mouse Hippocampus. Cereb Cortex 2018, 28:672-687.

42. Ma J, Yao XH, Fu Y, Yu YC: Development of layer 1 neurons in the mouse neocortex. Cereb Cortex 2014, 24:2604-2618.

43. Del Rio JA, Heimrich B, Super H, Borrell V, Frotscher M, Soriano E: Differential survival of Cajal-Retzius cells in organotypic cultures of hippocampus and neocortex. J Neurosci 1996, 16:6896-6907.

-44. Blanquie O, Liebmann L, Hubner CA, Luhmann HJ, Sinning A: NKCC1-Mediated GABAergic Signaling Promotes Postnatal Cell Death in Neocortical Cajal-Retzius Cells. Cereb Cortex 2017, 27:1644-1659.

In this study the authors, beyond confirming that electrical activity blockage had a survival effect on CRs, also found that silencing neural networks by activation of GABAa receptors induced CR death. This counterintuitive effect of GABA on CR survival was ascribed to the depolarising action of GABA on CRs, pointing to the role of GABA signalling in regulating CR demise. 
45. Louvi A, Yoshida M, Grove EA: The derivatives of the Wnt3a lineage in the central nervous system. J Comp Neurol 2007, 504:550-569.

-46. Anstotz M, Huang H, Marchionni I, Haumann I, Maccaferri G, Lubke JH: Developmental Profile, Morphology, and Synaptic Connectivity of Cajal-Retzius Cells in the Postnatal Mouse Hippocampus. Cereb Cortex 2016, 26:855-872.

The first study enlighting the specific dynamics of CR death in the hippocampus compared to the neocortex. Differences were found in delayed timing of CR disappearance, high percentage of persisting CRs and absence of activated Caspase 3 in degenerating cells. This contrasts with the behaviour of CRs in the neocortex (see ref. 37) suggesting that the environment plays a role in determining the lifespan of CRs and the pathway they undertake to die.

47. Kuida K, Haydar TF, Kuan CY, Gu Y, Taya C, Karasuyama H, Su MS, Rakic P, Flavell RA: Reduced apoptosis and cytochrome c-mediated caspase activation in mice lacking caspase 9. Cell 1998, 94:325-337.

48. Kuida K, Zheng TS, Na S, Kuan C, Yang D, Karasuyama H, Rakic P, Flavell RA: Decreased apoptosis in the brain and premature lethality in CPP32-deficient mice. Nature 1996, 384:368372.

49. Leonard JR, Klocke BJ, D'Sa C, Flavell RA, Roth KA: Strain-dependent neurodevelopmental abnormalities in caspase-3-deficient mice. J Neuropathol Exp Neurol 2002, 61:673-677.

50. Rehen SK, McConnell MJ, Kaushal D, Kingsbury MA, Yang AH, Chun J: Chromosomal variation in neurons of the developing and adult mammalian nervous system. Proc Natl Acad Sci U S A 2001, 98:13361-13366.

51. Nonomura K, Yamaguchi Y, Hamachi M, Koike M, Uchiyama Y, Nakazato K, Mochizuki A, Sakaue-Sawano A, Miyawaki A, Yoshida H, et al.: Local apoptosis modulates early mammalian brain development through the elimination of morphogen-producing cells. Dev Cell 2013, 27:621-634.

52. Sekine K, Kubo KI, Nakajima K: How does Reelin control neuronal migration and layer formation in the developing mammalian neocortex? Neurosci Res 2014, 86C:50-58.

53. Borello U, Pierani A: Patterning the cerebral cortex: traveling with morphogens. Curr Opin Genet Dev 2010, 20:408-415.

54. Barber M, Arai Y, Morishita Y, Vigier L, Causeret F, Borello U, Ledonne F, Coppola E, Contremoulins V, Pfrieger FW, et al.: Migration Speed of Cajal-Retzius Cells Modulated by Vesicular Trafficking Controls the Size of Higher-Order Cortical Areas. Curr Biol 2015, 25:2466-2478.

55. Griveau A, Borello U, Causeret F, Tissir F, Boggetto N, Karaz S, Pierani A: A novel role for Dbx1derived Cajal-Retzius cells in early regionalization of the cerebral cortical neuroepithelium. PLoS Biol 2010, 8:e1000440.

56. Niquille M, Garel S, Mann F, Hornung JP, Otsmane B, Chevalley S, Parras C, Guillemot F, Gaspar $P$, Yanagawa $Y$, et al.: Transient neuronal populations are required to guide callosal axons: a role for semaphorin 3C. PLoS Biol 2009, 7:e1000230.

57. Caronia-Brown G, Grove EA: Timing of cortical interneuron migration is influenced by the cortical hem. Cereb Cortex 2011, 21:748-755.

58. Fogarty CE, Bergmann A: The Sound of Silence: Signaling by Apoptotic Cells. Curr Top Dev Biol 2015, 114:241-265.

59. Fuchs Y, Steller H: Live to die another way: modes of programmed cell death and the signals emanating from dying cells. Nat Rev Mol Cell Biol 2015, 16:329-344.

60. Freret-Hodara B, Cui Y, Griveau A, Vigier L, Arai Y, Touboul J, Pierani A: Enhanced Abventricular Proliferation Compensates Cell Death in the Embryonic Cerebral Cortex. Cereb Cortex 2017, 27:4701-4718.

61. Luhmann HJ: Cajal-Retzius and Subplate cells: Transient Cortical neurons and Circuits. Comprehensive Developmental Neuroscience: Cellular migration and formation of neuronal connections 2013, Academin Press:843-856.

62. Akbarian S, Kim JJ, Potkin SG, Hetrick WP, Bunney WE, Jr., Jones EG: Maldistribution of interstitial neurons in prefrontal white matter of the brains of schizophrenic patients. Arch Gen Psychiatry 1996, 53:425-436. 
63. Crawford AH, Tripathi RB, Richardson WD, Franklin RJ: Developmental Origin of Oligodendrocyte Lineage Cells Determines Response to Demyelination and Susceptibility to Age-Associated Functional Decline. Cell Rep 2016, 15:761-773. .

64. Meyer G, Gonzalez-Gomez M: The heterogeneity of human Cajal-Retzius neurons. Semin Cell Dev Biol 2018, 76:101-111.

\section{Figure Legends}

\section{Figure 1}

Cell populations subjected to postnatal developmental death. (a) Cajal-Retzius cells (CRs, orange), cortical plate transient neurons (CPTs, purple), the first wave of oligodendrocyte precursors (firstOPCs, yellow) and subplate cells (SPs, green) are almost completely eliminated whereas cortical interneurons (INs, red) and glutamatergic projection neurons (GPNs, blue) are subjected to partial elimination. (b), (c) and (d) Extrapolated temporal windows of cell death and dynamics of disappearance of these populations are indicated with the same color code. Subtle differences might exist between populations, however they all undergo cell death within the first two postnatal weeks. Dashed lines for SPs and firstOPCs indicate the absence of precise time course.

\section{Figure 2}

Significance of cell death in the developing cortex. Apoptosis could reflect the elimination of cells which are abnormal (a), inappropriately embedded in cortical networks (b), that have become unnecessary or detrimental (c) and (d), but could also be used to provide additional space (e) or deliver a last signal (f) to neighbor cells. Populations that are subjected to partial or complete removal may fit in one or several of the situations depicted. 
(a)

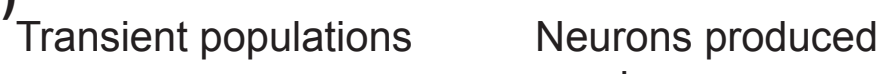

\section{Elimination Refinement}

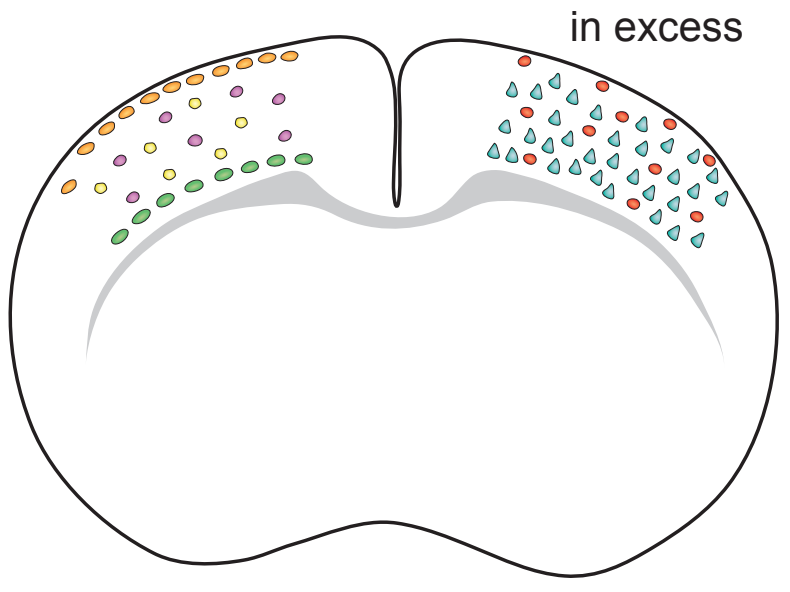
$\bigcirc$ CR
- CPT
firstOPC
$\bigcirc$ SP
○ GPN
- IN
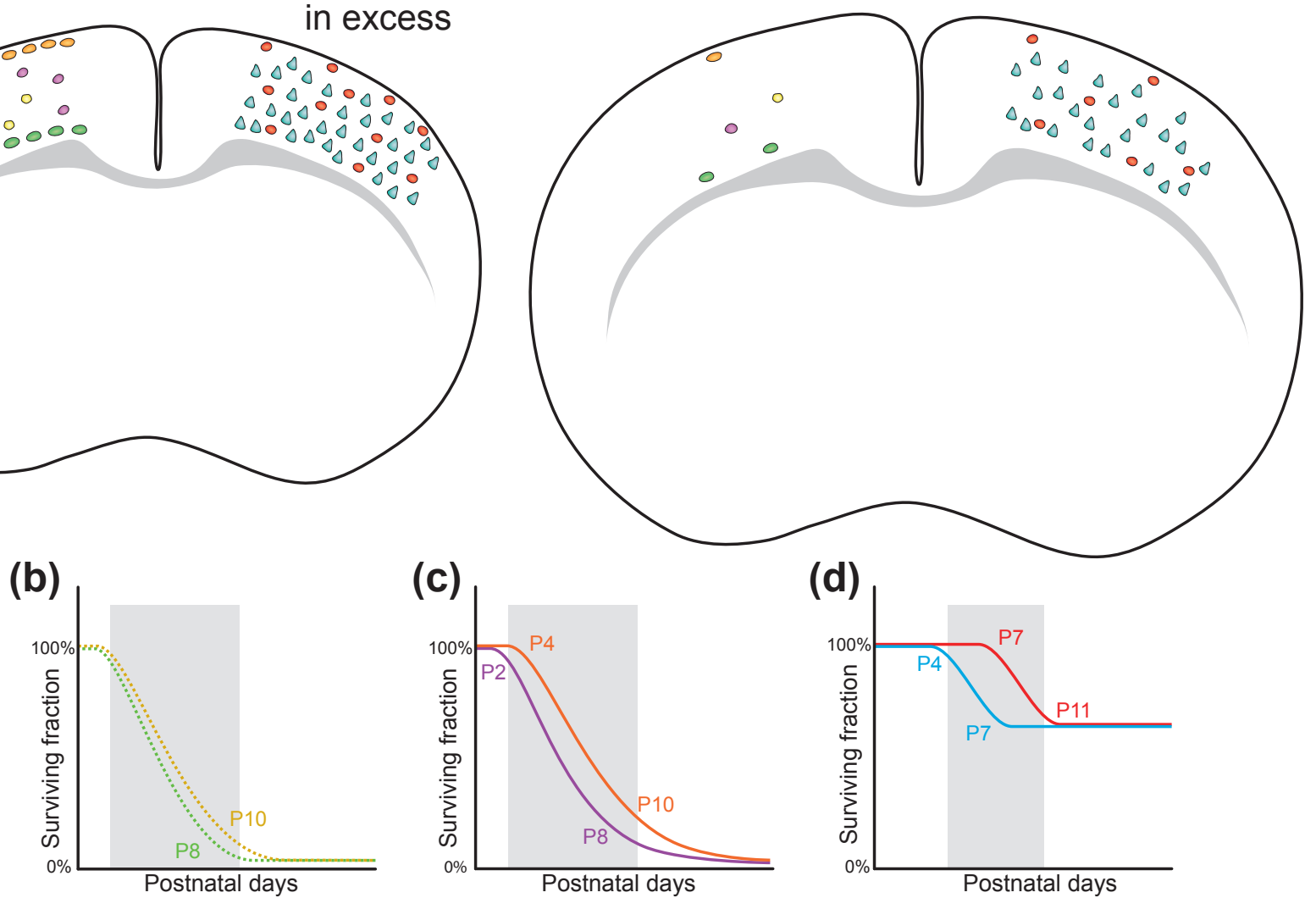

(d)

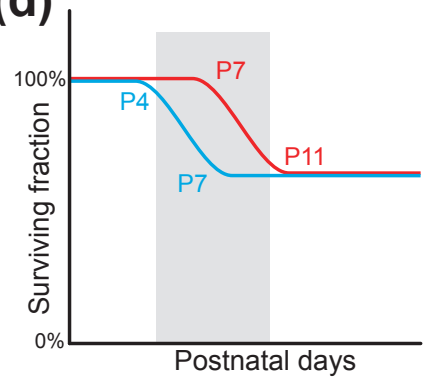


(a) Removal of abnormal cells

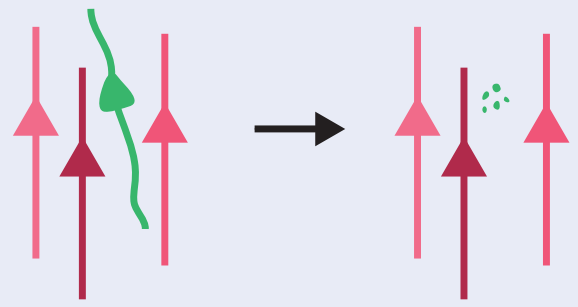

(c) Signal removal
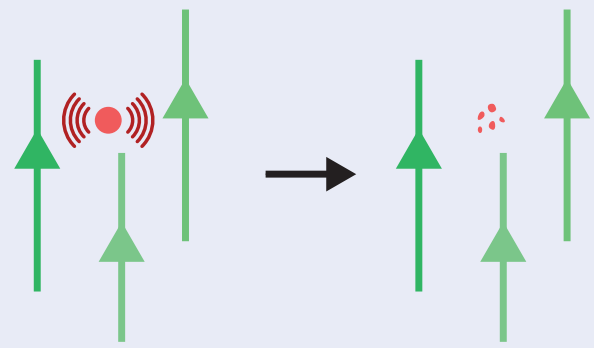

(e) Clear extra space

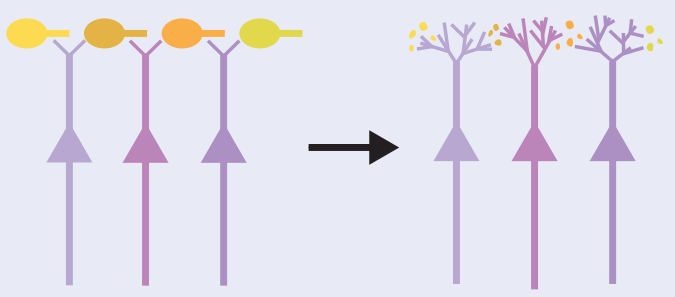

(b) Circuit maturation

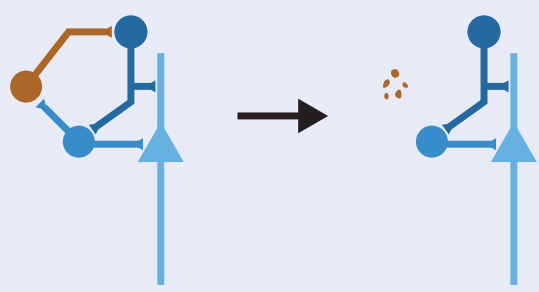

(d) Intermediate target removal

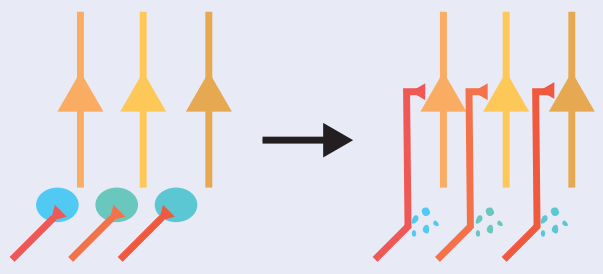

(f) Death as a signal

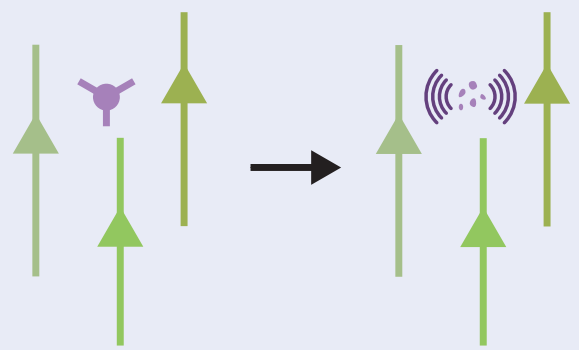


Table 1

Studies that characterized naturally occurring cell death of specific populations in the cerebral cortex

\begin{tabular}{|c|c|c|c|c|}
\hline Cell population & Reference & Method & Stages & notes \\
\hline IN & {$\left[10^{\bullet}\right]$} & Casp3 $^{+} / \mathrm{GAD} 67-\mathrm{GFP}^{+}$cells & Peak of death at P7-P11 & \\
\hline IN & {$\left[10^{\bullet}\right]$} & Total GAD67-GFP ${ }^{+}$cells & 40\% decline between P5 and P20 & \\
\hline IN & {$\left[27^{\bullet \bullet}\right]$} & Casp $^{+} / 5 \mathrm{HT} \mathrm{aR}^{\mathrm{eGFP}+}$ cells & Peak of death at P9 & $\begin{array}{l}\text { Only CGE-derived IN } \\
\text { are labeled }\end{array}$ \\
\hline IN & {$\left[27^{\bullet \bullet}\right]$} & Total 5HT3aR ${ }^{\text {eGFP+ }}$ cells & 20\% decline between P5 and P21 & $\begin{array}{l}\text { Only CGE-derived IN } \\
\text { are labeled }\end{array}$ \\
\hline $\begin{array}{l}\text { Cortical neurons } \\
\text { (mostly glutamatergic) }\end{array}$ & {$\left[26^{\bullet \bullet}\right]$} & Casp3 $^{+}$and $\mathrm{TUNEL}^{+}$cells in the primary motor cortex & Peak of death at P4-P7 & \\
\hline Cortical cells & {$\left[11^{\bullet}\right]$} & $\begin{array}{l}\text { TUNEL }^{+} \text {cells in the primary and secondary } \\
\text { somatosensory cortex }\end{array}$ & Peak of death at P4-P6 & \\
\hline CR & {$\left[15^{\bullet}\right]$} & 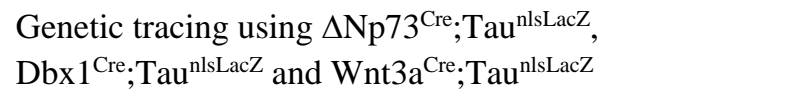 & $\begin{array}{l}\text { Most CR disappear between P4 and P10 } \\
\text { 95\% loss at P21 }\end{array}$ & $\begin{array}{l}\text { Regions/subpopulation } \\
\text { s differences }\end{array}$ \\
\hline CR & [39] & Ebf2-GFP ${ }^{+} /$Reelin $^{+}$cells in the somatosensory cortex & $\begin{array}{l}\text { 60\% loss between P2 and P6 } \\
80 \% \text { loss between P2 and P13 }\end{array}$ & $\begin{array}{l}\text { Not all CR subtypes } \\
\text { are labeled }\end{array}$ \\
\hline CR & [39] & $\begin{array}{l}\text { Time-lapse imaging of Ebf2-GFP }{ }^{+} \text {cells using cranial } \\
\text { windows }\end{array}$ & Most CR disappear between P7-P15 & $\begin{array}{l}\text { Not all CR subtypes } \\
\text { are labeled }\end{array}$ \\
\hline CR & [38] & CxCR4-EGFP & $\begin{array}{l}\text { CR nearly completely disappeared at P14 in } \\
\text { the neocortex }\end{array}$ & No quantification \\
\hline CR & [38] & $\begin{array}{l}\text { Genetic tracing using Wnt3aCre;Rosa26 } 6^{\text {Tomato }} \text { and } \\
\text { PDE1c }{ }^{\text {Cre. }} \text {;Rosa }\end{array}$ & 50\% loss between P7 and P14 & $\begin{array}{l}\text { Around } 20 \% \text { of CR } \\
\text { cells are not labeled }\end{array}$ \\
\hline CR & {$[42]$} & $\begin{array}{l}\text { Reelin }{ }^{+} / G A D 67-G F P^{-} \text {cells in primary motor, } \\
\text { somatosensory and visual areas }\end{array}$ & $\begin{array}{l}\text { Around } 50 \% \text { reduction in CR density } \\
\text { between P4 and P6. } \\
\text { Almost complete loss at P14 }\end{array}$ & $\begin{array}{l}\text { Minor differences } \\
\text { between areas }\end{array}$ \\
\hline $\mathrm{CPT}$ & {$\left[13^{\bullet}\right]$} & Genetic tracing using Dbx1 $1^{\text {Cre }} ; \mathrm{Tau}^{\mathrm{nlsLacZ}}$ & $\begin{array}{l}\text { Most CPT disappear between P0 and P8 } \\
95 \% \text { loss in adults }\end{array}$ & \\
\hline first OPC & {$\left[12^{\bullet}\right]$} & $\begin{array}{l}\text { Genetic tracing using Nkx2.1-Cre;Rosa26R-GFP in the } \\
\text { motor cortex combined with Sox10 immunostaining }\end{array}$ & Almost complete loss between P0 and P10 & \\
\hline SP & [3] & Cells labeled with BrdU between E10.5 and E12.5 & Almost complete loss between P0 and P8 & \\
\hline
\end{tabular}


Studies focusing on the disappearance of cortical interneurons (IN), glutamatergic projection neurons, Cajal-Retzius cells (CR), cortical plate transient cells (CPT), the first wave of oligodendrocyte precursors (first OPC) and subplate cells (SP). A brief description of the labeling techniques as well as the mouse strains used by the authors is indicated. Most of these cells disappear during the first two postnatal weeks, with variations between and among populations. 